\title{
Comprehensive geriatric assessment in patients undergoing transcatheter aortic valve implantation - results from the CGA- TAVI multicentre registry
}

Andrea Ungar ${ }^{1 *}$, Giulio Mannarino ${ }^{1}$, Nathalie van der Velde², Jan Baan³, Marie-Pierre Thibodeau4, Jean-Bernard Masson ${ }^{4}$, Gennaro Santoro ${ }^{1}$, Martijn van Mourik ${ }^{3}$, Sofie Jansen², Cornelia Deutsch ${ }^{5}$,

Peter Bramlage ${ }^{5}$, Jana Kurucova ${ }^{6}$, Martin Thoenes ${ }^{6}$, Stefania Maggi ${ }^{7}$ and Andreas W. Schoenenberger ${ }^{8}$

\begin{abstract}
Background: In older patients with aortic stenosis (AS) undergoing TAVI, the potential role of prior CGA is not well established. To explore the value of comprehensive geriatric assessment (CGA) for predicting mortality and/or hospitalisation within the first 3 months after transcatheter aortic valve implantation (TAVI).

Methods: An international, multi-centre, prospective registry (CGA-TAVI) was established to gather data on CGA results and medium-term outcomes in geriatric patients undergoing TAVI. Logistic regression was used to evaluate the predictive value of a multidimensional prognostic index (MPI); a short physical performance battery (SPPB); and the Silver Code, which was based on administrative data, for predicting death and/or hospitalisation in the first 3 months after TAVI (primary endpoint).
\end{abstract}

Results: A total of 71 TAVI patients (mean age 85.4 years; mean log EuroSCORE I 22.5\%) were enrolled. Device success according to VARC criteria was 100\%. After adjustment for selected baseline characteristics, a higher (poorer) MPI score (OR: 3.34; 95\% Cl: 1.39-8.02; $p=0.0068$ ) and a lower (poorer) SPPB score (OR: 1.15; 95\% Cl: 1.01-1.54; $p=0.0380$ ) were found to be associated with an increased likelihood of the primary endpoint. The Silver Code did not show any predictive ability in this population.

Conclusions: Several aspects of the CGA have shown promise for being of use to physicians when predicting TAVI outcomes. While the MPI may be useful in clinical practice, the SPPB may be of particular value, being simple and quick to perform. Validation of these findings in a larger sample is warranted.

Trial registration: The trial was registered in ClinicalTrials.gov on November 7, 2013 (NCT01991444).

Keywords: Transcatheter aortic valve implantation (TAVI), Comprehensive geriatric assessment (CGA), Multidimensional prognostic index (MPI), Short physical performance battery (SPPB), Silver code

\footnotetext{
*Correspondence: aungar@unifi.it

${ }^{1}$ Geriatric Intensive Care Unit, Department of Geriatrics and Medicine,

Careggi Hospital and University of Florence, Florence, Italy

Full list of author information is available at the end of the article
} 


\section{Background}

Severe symptomatic stenosis of the aortic valve (aortic stenosis; AS) is associated with mortality of up to $50 \%$ at 1 year if left untreated [1,2]. The outcome of surgical aortic valve replacement (SAVR) is generally predicted with the aid of quantitative scales such as the EuroSCORE or the Society of Thoracic Surgeons (STS) risk score. However, the accuracy of such algorithms for assessing older-age, multi-morbid patients undergoing transcatheter aortic valve implantation (TAVI) is low [3-5]. This is mainly due to the absence of variables related to ageing, such as frailty, mental status, social support, and overall health. There is evidence that additionally evaluating these factors can help provide a more precise estimation of an older person's response to treatment $[3,6,7]$. Indeed, a recent report from the American College of Cardiology (ACC) advocates assessment of frailty and cognitive function prior to determining a patient's suitability for TAVI [8]. The inclusion of a geriatrician in the Heart Team responsible for assessing patients prior to TAVI may therefore be warranted [9].

A comprehensive geriatric assessment (CGA) is a multidimensional diagnostic process for evaluating an individual's clinical, psychosocial, and functional characteristics $[10,11]$. It usually consists of functional tests complementing usual clinical evaluation. For example, CGA may include the calculation of a multidimensional prognostic index (MPI) based on mental and nutritional status, number of co-morbid conditions and medications, living arrangements, and the ability to cope with activities of daily living [12, 13]. Pilotto et al. showed that the MPI had high predictive power for assessing mortality after hospitalisation of older patients [13]. For TAVI specifically, few studies have evaluated CGA and its components for outcome prediction [3, 14-16]. For example, Stortecky et al. evaluated a geriatric assessment that contained many of the same components as the MPI, and found that many of the included items were predictive of mortality and the occurrence of a major adverse cardiac or cerebrovascular event (MACCE) at 30 days and 1 year after the procedure [14]. All previous studies originated from single-centre experiences.

We aimed to determine the power of CGA for predicting the combined endpoint of mortality and stroke within the 3 months subsequent to TAVI based on data from a multi-centre, prospective cohort. We further characterised changes in CGA over time, and provide additional evidence for the utility of TAVI in a geriatric, comorbid population.

\section{Methods}

\section{Patients and registry design}

The CGA-TAVI registry is a prospective, international, multi-centre, observational registry [17].
Patients were enrolled at three centres in Italy (Careggi Hospital, Florence), the Netherlands (Academic Medical Center, Amsterdam) and Canada (Centre Hospitalier de l'Université de Montréal) between August 2013 and December 2015. Individuals were eligible if they were aged $>80$ years, had symptomatic severe calcific aortic valve (AV) stenosis, and were assigned to undergo transaortic, transapical or transfemoral TAVI. Patients were excluded if TAVI was being performed as an emergency procedure or if patients were unable to participate in the followup. Overall, 603 patients underwent TAVI at one of the three study centres during the study period (Italy: 68, Canada: 95; the Netherlands: 440. Of these, 71 patients were enrolled in the CGA-TAVI registry: 41, 15 and 15 from the sites in Italy, Canada and the Netherlands, respectively.

\section{Baseline assessment}

A detailed description of the information documented has been previously published [17]. Briefly, data regarding demographics, comorbidities, and prior cardiovascular interventions were collected at hospital admission. A CGA was performed by a geriatrician for each patient. This included calculation of the MPI [12, 13], which consisted of the following components: Activities of Daily Living (ADL; 6 items) [18, 19]; Instrumental Activities of Daily Living (IADL; 8 items) [20]; Short Portable Mental Status Questionnaire (SPMSQ; 10 items) [21]; Cumulative Illness Rating Scale (CIRS; 14 items) [22, 23]; Mini Nutritional Assessment (MNA; 18 items) [24]; Exton-Smith Scale (ESS; 5 items) [25]; number of drugs used (1 item); and cohabitation status (1 item). In each case, a tripartite hierarchy was used for scoring (no problems: 0 points; minor problems: 0.5 points; severe problems: 1 point). The boundaries for these scores were based on the cut-off points derived from the associated literature [12]. A Silver Code value was also calculated from administrative data for further prognostic stratification [26] and a Short Physical Performance Battery (SPPB) was performed, which involved repeated chair stands, balance testing, and an $8-\mathrm{ft}$ $(2.44 \mathrm{~m})$ walk [27]. Detailed breakdowns of the three assessment scores can be found in Appendices 1, 2 (MPI), 3 (Silver Code) and 4 (SPPB). Procedural characteristics were also documented.

\section{Follow-up assessment and outcomes}

Patients were scheduled for follow-up at discharge, 30 days and 3 months post-procedure. These visits were conducted at the patient's enrolling centre and involved repetition of the CGA performed at the 
baseline assessment. Death, all-cause hospitalisation, TAVI-related hospitalisation, stroke, transient ischaemic attack (TIA), myocardial infarction (MI), lifethreatening bleeding, acute kidney injury, coronary artery obstruction requiring intervention, major vascular complications, valve dysfunction requiring repeat procedure, or worsening congestive heart failure (CHF) were recorded, as defined in the Valve Academic Research Consortium-2 (VARC-2) consensus document [28].

\section{Endpoints}

The primary endpoint was death and/or hospitalisation within the first 3 months after TAVI. The secondary endpoint was death and/or non-fatal stroke within the same period. Changes in the scores of the components of the CGA from baseline to 3 months were also evaluated.

\section{Data management and statistics}

Data were entered into an online database via the completion of an electronic case report form (eCRF; s4trials, Berlin, Germany). Details were automatically checked for plausibility and completeness.

Data were analysed using descriptive statistics, with categorical variables presented as absolute values and percentages and continuous variables as means with standard deviations (SD). A logistic regression was used to evaluate the predictive value of CGA components (MPI, SPBB and Silver Code) for the primary/ secondary endpoints. Age, gender, New York Heart Association (NYHA) class and surgical risk (EuroSCORE/STS) were used as co-variables. Logistic regression results are presented as odds ratios (OR) with 95\% Wald confidence limits (95\% CI) and $p$ values. CGA changes from baseline to 3 -month follow-up were tested for significance using a t-test. $P$-values of $<0.05$ were considered significant.

Data were analysed using IBM SPSS statistics version 24. (IBM corporation, Amonk, New York, USA).

\section{Results}

\section{Baseline patient characteristics}

Overall, 44 patients (62\%) were female. Means for age and body mass index (BMI) were $85.4 \pm 2.9$ years and $24.7 \pm 3.7 \mathrm{~kg} / \mathrm{m}^{2}$, respectively (Table 1 ). The most prevalent comorbidity was hypertension (83.1\%), followed by coronary artery disease (53.5\%), peripheral artery disease (28.2\%), diabetes mellitus (26.8\%), prior MI (23.9\%), and pulmonary disease $(15.5 \%)$. In terms of surgical risk, the mean $\log$ EuroSCORE and STS scores were $22.5 \pm 13.2 \%$ and $5.8 \pm 3.9 \%$, respectively.
Table 1 Patient characteristics

\begin{tabular}{|c|c|}
\hline & Mean \pm SD (n) / n/N (\%) \\
\hline Age [years] & $85.4 \pm 2.9(n=71)$ \\
\hline Gender [female] & $44 / 71(62.0)$ \\
\hline BMI $\left[\mathrm{kg} / \mathrm{m}^{2}\right]$ & $24.7 \pm 3.7(n=71)$ \\
\hline \multicolumn{2}{|l|}{ Comorbidities } \\
\hline Hypertension & $59 / 71(83.1)$ \\
\hline Diabetes mellitus & 19/71 (26.8) \\
\hline PAD & 20/71 (28.2) \\
\hline Prior stroke/TIA & 6/71 (8.5) \\
\hline CAD & $38 / 71(53.5)$ \\
\hline Prior Ml & 17/71 (23.9) \\
\hline Pulmonary disease $\mathrm{e}^{\mathrm{a}}$ & $11 / 71(15.5)$ \\
\hline Pulmonary hypertension & $35 / 71(49.3)$ \\
\hline Creatinine $\geq 2.0 \mathrm{mg} / \mathrm{dl}^{\mathrm{b}}$ & $5 / 71(7.0)$ \\
\hline Dialysis & 2/71 (2.8) \\
\hline \multicolumn{2}{|l|}{ Prior cardiovascular intervention } \\
\hline $\mathrm{PCl}$ & $16 / 71(22.5)$ \\
\hline CABG & 13/71 (18.3) \\
\hline Mitral valve replacement & 2/71 (2.8) \\
\hline Tricuspid valve replacement & $0 / 71(0)$ \\
\hline Balloon aortic valvuloplasty & $6 / 71(8.5)$ \\
\hline PPI & 5/71 (7.0) \\
\hline \multicolumn{2}{|l|}{ Surgical risk } \\
\hline Log EuroSCORE I & $22.5 \pm 13.2(n=71)$ \\
\hline STS risk score & $5.8 \pm 3.9(n=71)$ \\
\hline \multicolumn{2}{|l|}{ AS-related symptoms (\%) } \\
\hline Syncope & $5 / 71(7.0)$ \\
\hline Dizziness with exertion & $5 / 71(7.0)$ \\
\hline \multicolumn{2}{|l|}{ CCS angina grade } \\
\hline Class III & $7 / 70(10.0)$ \\
\hline Class IV & $0 / 70(0)$ \\
\hline \multicolumn{2}{|l|}{ NYHA classification } \\
\hline Class III & $50 / 71(70.4)$ \\
\hline Class IV & 7/71 (9.9) \\
\hline \multicolumn{2}{|l|}{ AS echocardiographic parameters } \\
\hline AV peak gradient $(\mathrm{mmHg})$ & $78.5 \pm 17.8(n=59)$ \\
\hline AV mean gradient $(\mathrm{mmHg})$ & $50.5 \pm 14.1(n=61)$ \\
\hline $\mathrm{V}_{\max }(\mathrm{m} / \mathrm{s})$ & $4.2 \pm 0.9(n=24)$ \\
\hline Effective orifice area $\left(\mathrm{cm}^{2}\right)$ & $0.9 \pm 0.6(n=37)$ \\
\hline LVEF (\%) & $50.9 \pm 12.0(n=62)$ \\
\hline
\end{tabular}

Legend: $B M I$ body mass index, $P A D$ peripheral artery disease, $T I A$ transient ischaemic attack, $C A D$ coronary artery disease, $M I$ myocardial infarction, $\mathrm{PCl}$ percutaneous coronary intervention, $C A B G$ coronary artery bypass grafting, PPI permanent pacemaker implantation, log Euro SCORE logistic European System for Cardiac Operative Risk Evaluation, STS Society of Thoracic Surgeons, AS aortic stenosis, LVEF left ventricular ejection fraction, $A V$ aortic valve, CCS Canadian Cardiovascular Society, NYHA New York Heart Association, $V_{\max }$ maximum velocity

${ }^{a}$ Defined as chronic obstructive pulmonary disease, asthma, a forced expiratory volume- 1 of $<1.0$, or oxygen dependency

${ }^{\mathrm{b}}$ Excluding patients with dialysis 
The majority of patients were at NYHA class III (70.4\%) or IV (9.9\%). Further AS-related symptoms were class III angina (10.0\%), dizziness with exertion (7.0\%), and syncope (7.0\%). Regarding echocardiography, peak and mean AV gradients were $78.5 \pm 17.8$ and $50.5 \pm 14.1 \mathrm{mmHg}$, respectively, with a left ventricular ejection fraction (LVEF) of $50.9 \pm 12.0 \%$, a mean $\mathrm{V}_{\max }$ of $4.2 \pm 0.9 \mathrm{~m} / \mathrm{s}$, and an effective orifice area of $0.9 \pm 0.6 \mathrm{~cm}^{2}$.

\section{Procedural characteristics and periprocedural outcomes}

Details about procedural aspects are provided in the supplementary data (Appendix 5). Devices were placed successfully (as defined by VARC-2 [28]) in all patients (Appendix 6). The rate of intraoperative complications was $17.1 \%$, which were vascular complications requiring treatment in $10.0 \%$ of patients and access-related in $5.6 \%$. No conversion to open surgery was necessary. Paravalvular regurgitation was moderate in $2.9 \%$, with no severe regurgitation. Postprocedural AV peak and mean gradients were $20.0 \pm$ 12.4 and $11.3 \pm 7.2 \mathrm{mmHg}$, respectively.

\section{Outcomes at 3-months}

In total, 6 patients died (8.5\%) and 9 were hospitalised $(13.8 \%)$ by the 3 -month follow-up. The primary endpoint (death and/or hospitalisation in the first 3 months) was observed in $13 / 71$ patients (18.3\%) (Table 2). After adjustment for baseline characteristics, a higher (poorer) MPI score (OR: 3.34; 95\% CI: $1.39-8.02 ; p=0.0068$ ) and a lower (poorer) SPPB

Table 2 Short- and medium-term outcomes

\begin{tabular}{lll}
\hline & $\begin{array}{l}\leq 30 \text { days }^{\mathrm{a}} \\
\mathrm{n} / \mathrm{N}(\%)\end{array}$ & $\begin{array}{l}\leq 3 \text { months } \\
\mathrm{n} / \mathrm{N}(\%)\end{array}$ \\
\hline $\begin{array}{l}\text { Primary endpoint } \\
\text { (Death and/or hospitalisation) }\end{array}$ & $5 / 70(7.1)$ & $13 / 71(18.3)$ \\
$\begin{array}{l}\text { Secondary endpoint } \\
\text { (Death and/or non-fatal stroke) }\end{array}$ & $2 / 71(2.8)$ & $6 / 71(8.5)$ \\
All-cause mortality & $2 / 71(2.8)$ & $6 / 71(8.5)$ \\
Non-fatal complications & $(n=69)$ & $(n=65)$ \\
All-cause hospitalisation & $5 / 69(7.2)$ & $9 / 65(13.8)$ \\
Valve-related hospitalisation & $3 / 69(4.3)$ & $2 / 65(6.2)$ \\
Non-fatal stroke & $0 / 69(0.0)$ & $0 / 62(0.0)$ \\
Acute kidney injury (stage 2 or 3) & $3 / 69(4.3)$ & $5 / 64(7.8)$ \\
Major vascular complication & $1 / 69(1.4)$ & $0 / 64(3.1)$ \\
Repeat procedure for valve dysfunction & $0 / 69(0)$ & $1 / 62(1.6)$ \\
Myocardial infarction & $0 / 69(0)$ & $0 / 62(0)$ \\
PPI & $9 / 69(13.0)$ & $9 / 65(13.8)$ \\
\hline
\end{tabular}

Legend: $C H F$ congestive heart failure, $M I$ myocardial infarction, NYHA New York Heart Association, CCS Canadian Cardiovascular Society, PPI permanent pacemaker implantation

${ }^{a} \leq 30$ days includes all complications which occurred periprocedurally, during the phase of hospitalisation for TAVI and after discharge within 30 days score (OR: $1.15 ; 95 \%$ CI: $1.01-1.54 ; p=0.0380$ ) were found to be associated with an increased odds of primary endpoint achievement (Table 3 ).

The secondary endpoint (death and/or non-fatal stroke in the first 3 months) was observed in 6 patients (8.5\%) (Table 2). After multivariate adjustment, a higher (poorer) MPI score (OR: 4.75 ; 95\% CI: $1.40-16.08 ; p=0.0123$ ) and a lower (poorer) SPPB score (OR: 1.62; 95\% CI: $1.08-2.43 ; p=0.0188$ ) were associated with a greater odds of secondary endpoint achievement (Table 3).

\section{CGA change from baseline to 3 months}

Between baseline and 3 months, the total MPI score decreased only slightly, from a mean of $0.34 \pm 0.11$ to $0.30 \pm 0.13$ (mean intra-individual change: $-0.02 \pm$ $0.12 ; p=0.25$ ) (Appendix 7). However, the CIRS and ESS components changed by a statistically significant amount $(-0.12 \pm 0.25 ; p<0.001$ and $-0.04 \pm 0.13$; $p=0.04$, respectively). While the change in Silver Code was small, the SPPB score increased significantly $(+1.86 \pm 2.76 ; \mathrm{p}<0.001)$.

\section{Discussion}

Of the multiple components of the CGA that were evaluated, the MPI and the SPPB both had value for predicting the likelihood of death and/or hospitalisation in the first 3 months following TAVI. In terms of time-efficiency, the SPPB appears to be the favourable approach, with the MPI perhaps not adding sufficient additional predictive value to warrant such a time-consuming assessment.

\section{Outcomes}

In our patients, the rate of all-cause mortality at 30 days $(2.8 \%)$ was within the range $(1.1 \%-5.9 \%)$ reported by large-scale studies in patients with a similar level of surgical risk and mean ages above 80 years, such as the PARTNER II trial and SOURCE 3, WIN-TAVI, Swiss TAVI, and PRAGMATIC registries [29-33]. Though a less commonly reported outcome, the same was true of the rate of rehospitalisation $(7.2 \%$ vs. $4.6 \%$ in the PARTNER II SAPIEN 3 trial and $6.5 \%$ in the overall PARTNER II trial) $[29,34]$. Variations in rates between studies are likely due to differing patient characteristics, access routes, and the valves/delivery devices available during study periods. Our findings regarding threemonth outcomes could not be easily compared to previous studies, as this time-point is not largely reported upon in the literature. 
Table 3 Logistic regression for the prediction of events at 3 months by CGA at baseline

\begin{tabular}{|c|c|c|c|c|}
\hline & Univariable OR (95\% Cl) & $p$-value & Multivariable OR $(95 \% \mathrm{Cl})$ & $p$-value \\
\hline \multicolumn{5}{|l|}{ Death and/or hospitalisation } \\
\hline Increasing MPI score (high vs. low) & $0.66(0.54-0.81)$ & $<0.0001$ & $3.34(1.39-8.02)^{\mathrm{a}}$ & 0.0068 \\
\hline Decreasing SPPB (low vs. high) & $1.35(1.19-1.53)$ & $<0.0001$ & $1.15(1.01-1.54)$ & 0.0380 \\
\hline Increasing Silver Code (high vs. low) & $0.94(0.92-0.97)$ & $<0.0001$ & $1.03(0.91-1.15)$ & 0.6576 \\
\hline \multicolumn{5}{|l|}{ Death and/or non-fatal stroke } \\
\hline Increasing MPI score (high vs. low) & $0.49(0.36-0.63)$ & $<0.0001$ & $4.75(1.40-16.08)$ & 0.0123 \\
\hline Decreasing SPPB (low vs. high) & $1.89(1.36-2.64)$ & 0.0002 & $1.62(1.08-2.43)$ & 0.0188 \\
\hline Increasing Silver Code (high vs. low) & $0.90(0.87-0.94)$ & $<0.0001$ & $1.04(0.87-1.23)$ & 0.6938 \\
\hline
\end{tabular}

Legend: MPI multidimensional prognostic index, SPPB short physical performance battery. All values adjusted for age, gender, NYHA class and surgical risk (EuroSCORE)

${ }^{a}$ The direction of the OR changed with the introduction of age into the model

\section{Surgical risk scores}

EuroSCORE and STS algorithms are conventional tools for assessing cardiac operative risk. It has been suggested that the latter is slightly more accurate in TAVI patients $[4,5]$, though neither are ideal. Patients in the present study had expected mortality rates of $22.5 \%$ (EuroSCORE I) and 5.8\% (STS), and though the latter was closer to the observed rate, both were excessively elevated. Even the more up-todate EuroSCORE II has been shown to have suboptimal discriminatory power, suggesting the need for alternative or additional assessment tools [35, 36].

\section{Multidimensional prognostic index}

Use of a CGA during clinical assessment of operative risk in AS patients has been suggested as a way to address the shortcomings of the EuroSCORE and STS score, and better predict outcomes $[17,36]$. In the present study, both MPI and SPPB were found to have predictive value for determining the likelihood of short-term mortality/hospitalisation or stroke after TAVI. Interestingly, while high MPI was a "negative predictor" in the univariate analysis, it became a "positive predictor" after adjusting for age, gender, NYHA class and surgical risk. This change of direction can be explained by the clinical setting; younger patients with a low MPI are typically treated with SAVR, while elderly patients with a high MPI are unlikely to be treated at all. Consequently, our TAVI population was likely composed of patients with a lower age and high MPI or a higher age and low MPI, resulting in a switch of the direction of the odds ratio at multivariate analysis. This reflection of the clinical context is supportive of the "real" association between MPI score and outcomes.

Though no other studies appear to have specifically reported on the predictive value of MPI in
TAVI, several have shown higher MPI scores to be significantly associated with greater rates of mortality in older patients with a variety of acute illnesses, including heart failure and TIA [12, 13, 37-40]. Other studies have evaluated other multi-component models for predicting mortality and morbidity after cardiac surgery [41]. For TAVI specifically, Green et al. found that patients with a high frailty score, as determined by gait speed, grip strength, serum albumin and ADL, were at greater risk of one-year mortality [15]. The five-component frailty score proposed by Kamga et al. was found to predict one-year mortality after transfemoral TAVI [16]. Stortecky et al. identified numerous parameters in their Multidimensional Geriatric Assessment that were predictive of 30-day and one-year mortality and MACCE after TAVI [14]. Data from the PARTNER trial were used to construct models for predicting a poor outcome, defined as death or a low/significantly decreased quality of life, after TAVI [42]. These models were subsequently validated in a large multi-centre cohort of TAVI patients, with an incremental increase in discriminative ability identified on the addition of markers of frailty and disability [43]. In agreement with the data from our CGA registry, these studies demonstrate the potential value of such multicomponent analyses for predicting outcome after TAVI.

\section{Short physical performance battery}

A significant drawback of these multidimensional evaluation tools, however, is that they are extremely time-consuming. In the present work, we found that use of the SPPB alone was equally as effective as the MPI for predicting death and/or hospitalisation, and death and/or non-fatal stroke, in the first 3 months after TAVI. This short series of tests is 
recommended by the European Union Geriatric Medicine Society (EUGMS) as part of a CGA in older AS patients [17], although it appears that there is little published evidence in support of using it for assessing TAVI candidates specifically. The concept of tests of physical ability to predict outcome after cardiac surgery has been evaluated in other studies. Afilalo et al. demonstrated that a slow 5-m gait speed was associated with a greater risk of operative mortality and in-hospital mortality and major morbidity in older patients undergoing cardiac surgery [7, 44]. They further determined that use of this parameter alone was superior to a variety of other frailty scales [6]. In patients undergoing TAVI specifically, 5-m gait speed has been shown to be independently associated with 30-day mortality after adjustment for STS score and other relevant baseline characteristics [45]. Stortecky et al. reported that the "timed get-up and go" (TUG) test had the greatest predictive ability of all of the individual geriatric assessment tools that they investigated [14]. In combination with either the STS or EuroSCORE, the TUG was superior to the other components evaluated for predicting all-cause mortality and MACCE during the first year after TAVI. A recent report by the ACC recommends that a $5-\mathrm{m}$ gait speed test and a 6 min walk test be used to assess frailty and physical functioning, respectively, when determining a patient's suitability for TAVI [8].

The simplicity of physical tests such as the SPPB is not their only advantage, with the lack of subjectivity on the part of both physician and patient providing a level of accuracy that cannot be obtained using questionnaire-based assessment. This is particularly relevant for the advanced-age TAVI population, where cognitive impairment is a potentially significant confounding factor when evaluating self-reported parameters [6].

\section{Silver code}

According to our data, the Silver Code had no value for predicting death/hospitalisation or death/stroke during the first 3 months after TAVI. The calculation of this parameter prior to deciding on the suitability of a patient for TAVI is another recommendation of the EUGMS [17]. Previous studies have demonstrated a relationship between Silver Code and one-year mortality, although this was in the setting of the Emergency Department $[26,46]$. As the Silver Code is determined from administrative data, it is particularly suited to planned procedures such as TAVI. Therefore, although it was not found to be an independent predictor of outcome in the present analysis, it should perhaps not be discounted. Further evaluation in a larger population may clarify its utility as part of a CGA prior to TAVI.

\section{Limitations}

Firstly, as an observational study, inherent limitations such as a higher potential for missing data are present. However, the observational aspect carried several advantages, such as an evaluation of TAVI patients in a real-world setting, avoiding the confounding issue of the strict inclusion and exclusion criteria used for clinical trials. This is particularly important, as geriatric patients are often those excluded due to high levels of comorbidity. Secondly, our findings are currently only applicable to geriatric patients at higher surgical risk. Considering that there is a current shift in clinical practice towards TAVI in lower-risk patients who are normally eligible for surgical heart valve replacement, re-evaluation of CGA in different populations may become necessary. In addition, we were only able to obtain data for a modest number of patients from three participating sites, limiting statistical power and generalisability. Indeed, the relatively low incidence of mortality and stroke at 3 months in a fairly small sample may have resulted in suboptimal power to detect baseline characteristics that are predictive for this outcome. Future studies in larger samples would be useful for clarification.

\section{Conclusion}

Several aspects of the CGA have shown promise for being of use to physicians when predicting the likelihood of death, rehospitalisation and non-fatal stroke following TAVI. The strong association between MPI and such outcomes indicates its potential utility in clinical practice. In addition, the SPPB may have significant value, being simple and quick to perform; however, the modest sample size included herein limit the formation of firm conclusions, and validation of these findings in a larger sample of TAVI patients with a greater range of surgical risk is warranted.

\section{Clinical perspectives}

The accuracy of conventional surgical risk scores is known to be suboptimal for predicting the outcomes of TAVI in elderly aortic stenosis patients. This study shows a potential benefit of adding items from a comprehensive geriatric assessment (CGA) to preintervention assessments. This now requires further validation in larger cohorts. 


\section{Appendix 1}

Provides an overview about the Multidimensional Prognostic Index (MPI).

Table 4 Calculation of the Multidimensional Prognostic Index (MPI)

\begin{tabular}{|c|c|c|c|}
\hline & \multicolumn{3}{|l|}{ Problem severity } \\
\hline & No (=0 points) & Minor (= 0.5 points) & Severe $(=1$ point $)$ \\
\hline 1. Co-habitation status & Living with relatives/nurse & Living in an institution & Living alone \\
\hline 2. Current medication use & $0-3$ medications & 4-6 medications & $\geq 7$ medications \\
\hline 3. ADL score & $6-5$ & $4-3$ & $2-0$ \\
\hline 4- IADL score & $8-6$ & $5-4$ & $3-0$ \\
\hline 5. SPMSQ score & $0-3$ & $4-7$ & $8-10$ \\
\hline 6. ESS score & $16-20$ & $10-15$ & $5-9$ \\
\hline 7. $\mathrm{CIRS} \mathrm{Cl}$ & 0 & $1-2$ & $\geq 3$ \\
\hline 8. MNA score & $\geq 24$ & $17-23.5$ & $<17$ \\
\hline \multicolumn{4}{|c|}{ Total MPI score (sum of points/8): } \\
\hline Low-risk: & \multicolumn{3}{|l|}{$\leq 0.33$} \\
\hline Moderate-risk: & \multicolumn{3}{|l|}{$0.34-0.66$} \\
\hline High-risk: & \multicolumn{3}{|l|}{$>0.66$} \\
\hline
\end{tabular}

Legend: $A D L$ activities of daily living, IADL instrumental ADL, SPMSQ short portable mental status questionnaire, ESS Exton-Smith scale, CIRS cumulative illness raiting scale, $\mathrm{Cl}$ comorbidity index, MNA mini nutritional assessment, MPI multidimensional prognostic index. The numbering on the left-hand side of factors corresponds to the numbering in Appendix 2

\section{Appendix 2}

Provides a breakdown of the Multidimensional Prognostic

Index (MPI).

Table 5 Breakdown of MPI Scoring

3. Activities of Daily Living (ADL)

Bathing (sponge bath, tub bath, or shower)

Receives no assistance (gets in and out of the tub by self if tub is usual means of bathing) 1

Receives no assistance in bathing only one part of the body (such as back or leg) 1

Receives assistance in bathing more than one part of the body (or not bathed)

Dressing (gets clothes from closets and drawers, including underclothes/outer garments and using fasteners/ braces, if worn)

Gets clothes and gets completely dressed without assistance

Gets clothes and gets dressed without assistance except for assistance in tying shoes

Receives assistance in getting clothes or in getting dressed, or stays partly or completely undressed 0

Toileting

Goes to "toilet room" cleans self, and arranges clothes without assistance (may use object for support such as cane, walker, or wheelchair and may manage night bedpan or commode, emptying same in morning)

Receives assistance in going to "toilet room" or in cleaning self or in arranging clothes after elimination or in use of night bedpan or commode

Doesn't go to room termed "toilet" for the elimination process

Transfer

Moves in and out of bed as well as in and out of chair without assistance (may be using object for 1 support such as cane or walker)

Moves in and out of bed or chair with assistance

0

Doesn't get out of bed

Continence 
Table 5 Breakdown of MPI Scoring (Continued)

Controls urination and bowel movement completely by self

Has occasional "accidents"

Supervision helps keep urine or bowel control, catheter is used, or is incontinent

Feeding

Feeds self without assistance

Feeds self except for getting assistance in cutting meat or buttering bread

Receives assistance in feeding or is fed partly or completely by using tubes or intravenous fluids

Max ADL score (best performance):

4. Instrumental Activities of Daily Living Scale (IADL)

Ability to use telephone

Operates telephone on own initiative: looks up and dials numbers, etc.

Dials a few well-known numbers

Answers telephone but does not dial

Does not use telephone at all

Shopping

Takes care of all shopping needs independently

Shops independently for small purchases

Needs to be accompanied on any shopping trip

Completely unable to shop

Food preparation

Plans, prepares and serves adequate meals independently

Prepares adequate meals if supplied with ingredients

Heats, serves and prepares meals or prepares meals but does not maintain adequate diet

Needs to have meals prepared and served

Housekeeping

Maintains house alone or with occasional assistance (e.g. "heavy work domestic help") 1

Performs light daily tasks such as dishwashing, bed-making

Performs light daily tasks but cannot maintain acceptable level of cleanliness

Needs help with all home maintenance tasks 0

$\begin{array}{ll}\text { Does not participate in any housekeeping tasks } & 0\end{array}$

Laundry

Does personal laundry completely

Launders small items; rinses stockings, etc.

All laundry must be done by others

Mode of transportation

Travels independently on public transportation or drives own car

Arranges own travel via taxi, but does not otherwise use public transportation

Travels on public transportation when accompanied by another 1

Travel limited to taxi or automobile with assistance of another 0

Does not travel at all 0

Responsibility for own medications

Is responsible for taking medication in correct dosages at correct time 1

Takes responsibility if medication is prepared in advance in separate dosage $\quad 0$

Is not capable of dispensing own medication 0 
Table 5 Breakdown of MPI Scoring (Continued)

Ability to handle finances

Manages financial matters independently (budgets, writes checks, pays rent, bills, goes to bank), collects and keeps track of income

Manages day-to-day purchases, but needs help with banking, major purchases, etc

Incapable if handling money

Max IADL score (best performance):

5. Short Portable Mental Status Questionnaire (SPMSQ)

What is the date today? (Correct only when the month, date, and year are all correct)

If incorrect: 1

What day of the week is it?

If incorrect: 1

What is the name of this place? (Correct if any of the description of the location is given)

If incorrect: 1

What is your street address?

If incorrect: 1

How old are you?

If incorrect: 1

When were you born?

If incorrect: 1

Who is the president (or the Pope) now? (Requires only the correct last name)

If incorrect: 1

Who was president (or the Pope) just before him?

If incorrect: 1

What was your mother's maiden name?

If incorrect: 1

Subtract 3 from 20 and keep subtracting 3 from each new number at least for 3 times (the entire series must be performed correctly to be scored as correct)

Max SPMQ score (worst performance):

If incorrect: 1

6. Exton-Smith Scale (ESS)

General Condition

$\mathrm{Bad}$

Poor

Fair

Good

Mental State

Stuporous

Confused

Apathetic

Alert

Activity

In bed all day

Chairfast

Walks with help

Ambulant

Incontinence

Doubly incontinent

Usually of urine

Occasional

None

Mobility in Bed

Immobile

Very limited 
Table 5 Breakdown of MPI Scoring (Continued)

Max ESS score (best performance):

7. Cumulative Illness Rating Scale

Cardiac (heart only)

Hypertension (rating is based on severity)

Vascular (arteries, veins, lymphatics)

Respiratory (lungs, bronchi, trachea)

EENT (eye, ear, nose, throat, larynx)

Upper GI (esophagus, stomach, duodenum, biliary and pancreatic trees)

Lower Gl (intestines, hernias)

Hepatic (liver only)

Renal (kidneys only)

Other GU (urethers, bladder, urethra, prostate, genitals)

Musculo-skeletal-integumentary (muscles, bone, skin)

Neurological (brain, spinal cord, nerves)

Endocrine-metabolic (including diabetes, hyperlipidemia, infections, toxicity)

Psychiatric (dementia, depression, anxiety, agitation, psychosis)

Max comorbidity index (number of items with a score of $\geq 3$; excluding the psychiatric item; most severe):

8. Mini Nutritional Assessment (MNA)

Anthropometric Assessment

Body Mass Index

$<19$

$19-20$

$21-22$

$\geq 23$

Mid-arm circumference $(\mathrm{cm})$

$<21$

22

$>22$

Calf circumference $(\mathrm{cm})$

$<31$

$>31$

Weight loss (last 3 months)

Loss of $>3 \mathrm{~kg}$

Do not know

Loss between 1 and $3 \mathrm{~kg}$

No weight loss

General Assessment

Lives independently (not in a nursing home or hospital)

No

Yes

Takes more than 3 prescription drugs per day
20

$\begin{array}{lllll}\begin{array}{l}\text { Point allocation based on disease severity } \\ \text { None }\end{array} & \text { Mild } & \text { Moderate } & \text { Severe } & \begin{array}{l}\text { Extremely } \\ \text { severe }\end{array} \\ 1 & 2 & 3 & 4 & 5 \\ 1 & 2 & 3 & 4 & 5 \\ 1 & 2 & 3 & 4 & 5 \\ 1 & 2 & 3 & 4 & 5 \\ 1 & 2 & 3 & 4 & 5 \\ 1 & 2 & 3 & 4 & 5 \\ 1 & 2 & 3 & 4 & 5 \\ 1 & 2 & 3 & 4 & 5 \\ 1 & 2 & 3 & 4 & 5 \\ 1 & 2 & 3 & 4 & 5 \\ 1 & 2 & 3 & 4 & 5 \\ 1 & 2 & 3 & 4 & 5 \\ 1 & 2 & 3 & 4 & 5 \\ 1 & 2 & 3 & 4 & 5\end{array}$

13

Points 
Table 5 Breakdown of MPI Scoring (Continued)

No

\section{0}

Dietary Assessment

How many full meals does the patient eat daily?

1 meal

2 meals

3 meals

Consumes at least 1 serving of dairy products (milk, cheese, yogurt) per day

No

Yes

Consumes 2 or more servings of Legumes or eggs per week

No

Yes

Consumes meat, fish or poultry every day

No

Yes

Consumes 2 or more servings of fruits or vegetables per day?

No

Yes

Has food intake declined over the past 3 months due to loss of appetite?

Severe loss of appetite

Moderate loss of appetite

No loss of appetite

How much fluids consumed per day?

$<5$ glasses

5-9 glasses

$>9$ glasses

Mode of feeding

With assistance

Self-feed with some difficulty

政

政

0

政

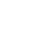

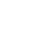

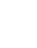

.


Table 5 Breakdown of MPI Scoring (Continued)

Self-feed without any problem

Self Assessment

Do they view themselves as having nutritional problems?

Major malnutrition

Does not know

No nutritional problems

In comparison with other people of same age, how they consider their health status?

Not as good

Does not know

As good

Better

Legend: The numbering on the left-hand side of score titles corresponds to the numbering of factors in Appendix 1

\section{Appendix 3}

Illustrates how the Silver Code is calculated.

Table 6 Calculation of the Silver Code

\begin{tabular}{|c|c|}
\hline Factor & Points \\
\hline \multicolumn{2}{|l|}{ Age } \\
\hline $75-79$ & 0 \\
\hline $80-84$ & 3 \\
\hline $85+$ & 9 \\
\hline \multicolumn{2}{|l|}{ Gender } \\
\hline Female & 0 \\
\hline Male & 2 \\
\hline \multicolumn{2}{|l|}{ Marital status } \\
\hline Married & 0 \\
\hline Unmarried/widowed/divorced & 1 \\
\hline \multicolumn{2}{|l|}{ Previous admission to a day hospital } \\
\hline No & 0 \\
\hline Yes & 5 \\
\hline \multicolumn{2}{|c|}{ Previous admission to a regular ward and discharge diagnosis } \\
\hline No admission (0) & 0 \\
\hline Respiratory disease (6) & 6 \\
\hline Cancer (11) & 11 \\
\hline Other (2) & 2 \\
\hline \multicolumn{2}{|c|}{ Number of drugs in the previous 3 mo } \\
\hline $0-8$ & 0 \\
\hline $8+$ & 2 \\
\hline \multicolumn{2}{|c|}{ Total score: 0 pts. = best possible performance, 36 pts. = worst possible performance- Corresponds to gradient risk for mortality } \\
\hline
\end{tabular}




\section{Appendix 4}

Describes the components of the Short Physical Performance

Battery (SPPB).

Table 7 Short Physical Performance Battery (SPPB)

\begin{tabular}{|c|c|}
\hline Instructions & Scoring \\
\hline \multicolumn{2}{|l|}{ 1. Repeated Chair Stands } \\
\hline $\begin{array}{l}\text { - Ask patient if they think it is safe for them to try and stand up from a chair five times without using their } \\
\text { arms. } \\
\text { - If yes, instruct patient to stand up straight and then sit back down again as quickly as they can five times, } \\
\text { without stopping in between, keeping their arms folded over their chest. } \\
\text { - Demonstrate. } \\
\text { - Begin the stopwatch when patient begins to stand up. Count aloud each time patient rises. } \\
\text { - Stop the stopwatch when subject has straightened up completely for the fifth time. Also stop if the } \\
\text { subject uses arms, if they have not completed rises after } 1 \text { min, or if concerned about their safety. }\end{array}$ & $\begin{array}{l}-<5 \text { stands completed in } \leq 1 \mathrm{~min}= \\
0 \text { pts. } \\
-5 \text { stands in }>16.7 \mathrm{~s} \text { and } \leq 1 \mathrm{~min}= \\
1 \mathrm{pt} \text {. } \\
-5 \text { stands in } 16.6-13.7 \mathrm{~s}=2 \mathrm{pts} \text {. } \\
-5 \text { stands in } 13.6-11.2 \mathrm{~s}=3 \mathrm{pts} \text {. } \\
-5 \text { stands in }<11.1 \mathrm{~s}=4 \mathrm{pts}\end{array}$ \\
\hline \multicolumn{2}{|l|}{ 2. Balance Testing } \\
\hline $\begin{array}{l}\text { Semitandem: } \\
\text { - Instruct patient to stand with the side of the heel of one foot touching the big toe of the other foot for } \\
10 \mathrm{~s} \text { (left/right feet as preferred by patient). } \\
\text { - Demonstrate } \\
\text { - Stand next to patient to help them into a semitandem position, allowing them to hold onto your } \\
\text { arms to establish balance. } \\
\text { - Begin timing when patient has the feet in position. } \\
\text { - If unable to hold the semitandem position for } 10 \mathrm{~s} \rightarrow \text { side-by-side. } \\
\text { - If able to hold the semitandem position for } 10 \mathrm{~s} \rightarrow \text { tandem. } \\
\rightarrow \text { Side-by-side: } \\
\text { As for semitandem but with feet together. Patients may use their arms, bend their knees, or move their } \\
\text { body to maintain balance, but may not move their feet. } \\
\rightarrow \text { Tandem: } \\
\text { As for semitandem but with the heel of one foot in-front-of and touching the toes of the other foot. }\end{array}$ & $\begin{array}{l}\text { - Side-by-side: }<10 \text { s or unable }= \\
0 \text { pts. } \\
\text { - Side-by-side: } \geq 10 \text { s; semitandem: } \\
<10 s=1 \text { pt. } \\
\text { - Semitandem: } \geq 10 \text { s; tandem: } \\
\text { 0-2 } s=2 \text { pts. } \\
\text { - Semitandem: } \geq 10 \text { s; tandem: } \\
\text { 3-9 } s=3 \text { pts. } \\
\text { - Tandem: } \geq 10 s=4 \text { pts }\end{array}$ \\
\hline \multicolumn{2}{|l|}{ 3. Eight-foot $(2.44 \mathrm{~m})$ walk } \\
\hline $\begin{array}{l}\text { - Instruct patient to walk at their usual pace to the other end of course (a distance of } 8 \mathrm{ft} \text { ) and to continue } \\
\text { walking until they pass the end of the tape. If they use a cane or other walking aid outside of their home, } \\
\text { they should use it for the test. } \\
\text { - Press the start button on the stopwatch as the participant begins walking. Walk with the patient. } \\
\text { - Measure the time they take to complete the } 8 \text {-ft course. }\end{array}$ & $\begin{array}{l}\text { - Unable to complete course = } \\
0 \text { pts. } \\
\text { - Completed course in }>5.7 \mathrm{~s}= \\
1 \text { pt. } \\
\text { - Completed course in } 4.1-6.5 \mathrm{~s}= \\
2 \text { pts. } \\
\text { - Completed course in } 3.2-4.0 \mathrm{~s}= \\
3 \text { pts. } \\
\text { - Completed course in }<3.1 \mathrm{~s}= \\
4 \text { pts }\end{array}$ \\
\hline $\begin{array}{l}\text { SPPB score: } 0 \text { pts. = worst possible performance, } 12 \text { pts. = best performance } \\
\text { Score corresponds to gradient risk for mortality, nursing home admission, and disability }\end{array}$ & \\
\hline
\end{tabular}

\section{Appendix 5}

Details about procedural aspects are provided.

Table 8 Procedural characteristics

\begin{tabular}{ll}
\hline & $\mathrm{n} / \mathrm{N}(\%)$ \\
\hline Access route & \\
Transfemoral & $55 / 71(77.5)$ \\
Transapical & $9 / 71(12.7)$ \\
Transaortic & $7 / 71(9.9)$ \\
Type of THV & \\
SAPIEN XT & $26 / 71(36.6)$ \\
SAPIEN 3 & $40 / 71(56.3)$ \\
Other & $5 / 71(7.0)$ \\
THV diameter & \\
23 mm & $37 / 70(52.9)$ \\
26 mm & $26 / 70(37.1)$ \\
29 mm & $7 / 70(10.0)$ \\
Second valve used & $2 / 71(2.8)$ \\
Pre-implantation balloon dilatation & $63 / 71(88.7)$ \\
Post-delivery balloon dilatation & $9 / 71(12.7)$ \\
\hline
\end{tabular}

Legend: THV transcatheter heart valve 


\section{Appendix 6}

Details about periprocedural outcomes are provided.

Table 9 Periprocedural outcomes

\begin{tabular}{|c|c|}
\hline & Mean \pm SD / n/N (\%) \\
\hline \multicolumn{2}{|l|}{ Device success (VARC-2) $)^{a}$} \\
\hline Absence of procedural mortality & $70 / 70(100.0)$ \\
\hline Correct positioning of THV & $70 / 70(100.0)$ \\
\hline Intended performance of THV & $70 / 70(100.0)$ \\
\hline Intraoperative complications ${ }^{b}$ & $12 / 70(17.1)$ \\
\hline Vascular complications requiring treatment ${ }^{c}$ & $7 / 70(10.0)$ \\
\hline Access-related complications (dissection, rupture) & 4/71 (5.6) \\
\hline Conversion to open surgery (\%) & $0 / 70(0.0)$ \\
\hline \multicolumn{2}{|l|}{ Paravalvular regurgitation (\%) } \\
\hline None/trace & $46 / 70(65.7)$ \\
\hline Mild & 22/70 (31.4) \\
\hline Moderate & 2/70 (2.9) \\
\hline Severe & $0 / 70(0.0)$ \\
\hline \multicolumn{2}{|l|}{ Transvalvular leakage (\%) } \\
\hline None/trace & $62 / 70(88.6)$ \\
\hline Mild & $8 / 70(11.4)$ \\
\hline Moderate/severe & 0/70 (0.0) \\
\hline AV peak gradient $(\mathrm{mmHg})$ & $20.0 \pm 12.4(n=31)$ \\
\hline AV mean gradient $(\mathrm{mmHg})$ & $11.3 \pm 7.2(n=32)$ \\
\hline \multicolumn{2}{|c|}{$\begin{array}{l}\text { Legend: } T H V \text { transcatheter heart valve, } A V \text { aortic valve } \\
\text { aValve Academic Research Consortium criteria: absence of procedural } \\
\text { mortality, correct positioning of a single prosthetic heart valve into proper } \\
\text { anatomical position, and intended performance of the prosthetic heart valve } \\
\text { (no prosthesis-patient mismatch) and mean aortic valve gradient } \\
\text { bIncludes access-related complications ( } 8 \text { pts), asystole/arrhythmia ( } 2 \mathrm{pts}) \text {, } \\
\text { haemorrhagic stroke (1 pt) [one patient no further information available] } \\
\text { 'Includes aneurysm, haematoma, pericardial haematoma/effusion (2 pts), } \\
\text { apical bleeding (1 pt) }\end{array}$} \\
\hline
\end{tabular}

\section{Appendix 7}

Changes of the CGA over 3 month.

\section{Abbreviations}

ACC: American College of Cardiology; AS: Aortic stenosis; AV: Aortic valve; BMI: Body mass index; CGA: Comprehensive geriatric assessment; CHF: Congestive heart failure; Cl: Confidence interval; CIRS: Cumulative illness rating scale; eCRF: Electronic case report form; ESS: Exton-Smith Scale; EUGMS: European union geriatric medicine society; IADL: Instrumental Activities of Daily Living; LVEF: Left ventricular ejection fraction; MACCCE: Major adverse cardiac or cerebrovascular event; MI: Myocardial infarction; MNA: Mini nutritional assessment; MPI: Multidimensional prognostic index; NYHA: New York Heart Association; OR: Odds ratio; SAVR: Surgical aortic valve replacement; SPMSQ: Short portable mental status questionnaire; SPPB: Short physical performance battery; STS: Society of thoracic surgeons; TAVI: Transcatheter aortic valve implantation; TIA: Transient ischaemic attack; TUG: Timed get-up and go; VARC: Valve Academic Research Consortium

\section{Acknowledgements}

Data were captured using the s4trials Software provided by Software for Trials Europe GmbH, Berlin, Germany. Helen Sims and Katherine Smith (Institute for Pharmacology and Preventive Medicine; IPPMed) provided editorial support during the preparation of this manuscript.

\section{Funding}

This work was supported by a research grant that was provided by Edwards Lifesciences (Nyon, Switzerland) to the Sponsor, IPPMed (Cloppenburg, Germany). JK and MT are representatives of the funder. They discussed the study design with the principal investigators and the sponsor, had no role in data collection, had no role in the analysis, but revised the manuscript along with the other authors for important intellectual content.

\section{Availability of data and materials}

The datasets used and/or analysed during the current study are available from the corresponding author upon reasonable request.

\section{Authors' contributions}

The authors take responsibility for all aspects of the reliability and freedom from bias of the data presented and their discussed interpretation. The specific contributions of the respective authors are as follows: AU, PB, JK, MT, SM and AWS were involved in the conception and design of the study; GM, NVV, MT, JB, MPT, JBM, GS, MvM, and SJ collected the data, which were analyzed by $A U, G M, C D$, and PB and interpreted by the author group; PB drafted the manuscript and all other authors revised the article for important intellectual content. All authors have given final approval for the version to be submitted.

Table 10 CGA baseline vs 3 months

\begin{tabular}{|c|c|c|c|c|c|c|c|c|}
\hline & \multicolumn{2}{|c|}{ Baseline } & \multicolumn{2}{|c|}{3 months } & \multicolumn{4}{|c|}{ Intra-individual change } \\
\hline & $\mathrm{N}$ & Mean \pm SD & $\mathrm{N}$ & Mean \pm SD & $\mathrm{N}$ & Mean \pm SD & $95 \% \mathrm{Cl}$ & $p$-value \\
\hline MPI total score & 71 & $0.34 \pm 0.11$ & 56 & $0.30 \pm 0.13$ & 56 & $-0.02 \pm 0.12$ & $-0.05,0.01$ & 0.25 \\
\hline $\mathrm{ADL}$ & 71 & $0.05 \pm 0.15$ & 60 & $0.07 \pm 0.22$ & 60 & $0.04 \pm 0.25$ & $-0.02,0.11$ & 0.20 \\
\hline IADL & 71 & $0.16 \pm 0.29$ & 60 & $0.21 \pm 0.32$ & 60 & $0.06 \pm 0.32$ & $-0.02,0.14$ & 0.16 \\
\hline SPMSQ & 71 & $0.01 \pm 0.06$ & 57 & $0.02 \pm 0.09$ & 57 & $0.01 \pm 0.12$ & $-0.02,0.04$ & 0.57 \\
\hline CIRS & 71 & $0.82 \pm 0.27$ & 56 & $0.71 \pm 0.38$ & 56 & $-0.12 \pm 0.25$ & $-0.18,-0.05$ & $<0.001$ \\
\hline MNA & 71 & $0.30 \pm 0.33$ & 56 & $0.21 \pm 0.28$ & 56 & $-0.07 \pm 0.37$ & $-0.17,0.03$ & 0.16 \\
\hline ESS & 71 & $0.08 \pm 0.22$ & 56 & $0.02 \pm 0.09$ & 56 & $-0.04 \pm 0.13$ & $-0.07,0.0$ & 0.04 \\
\hline Medication use & 71 & $0.86 \pm 0.24$ & 60 & $0.88 \pm 0.21$ & 60 & $0.04 \pm 0.27$ & $-0.03,0.11$ & 0.23 \\
\hline Co-habitation status & 71 & $0.42 \pm 0.50$ & 60 & $0.31 \pm 0.46$ & 60 & $-0.08 \pm 0.39$ & $-0.18,0.03$ & 0.14 \\
\hline Silver code & 71 & $22.53 \pm 6.44$ & 57 & $22.8 \pm 6.33$ & 57 & $-0.31 \pm 3.55$ & $-0.64,1.25$ & 0.52 \\
\hline SPPB & 71 & $5.69 \pm 3.33$ & 56 & $7.82 \pm 2.84$ & 56 & $1.86 \pm 2.76$ & $1.12,2.60$ & $<0.001$ \\
\hline
\end{tabular}

Legend: MPI Multidimensional Prognostic Index, ADL Activities of Daily Living, Instrumental Activities of Daily Living, SPMSQ Short Portable Mental Status Questionnaire, CIRS Cumulative Illness Rating Scale, MNA Mini Nutritional Assessment, ESS Exton-Smith Scale, SPPB short physical performance battery 


\section{Ethics approval and consent to participate}

All enrolled patients provided written informed consent. The study was conducted in accordance with the Declaration of Helsinki and approved by the responsible ethics committee at each participating site: Careggi Hospital, Florence, Italy (Comitato Etico Area Vasta Centro), Academic Medical Center, Amsterdam, the Netherlands (Medisch Ethische Toetsingscommissie) and Centre Hospitalier de I'Université de Montréal, Canada (Comite d'Ethique de la Recherche et du Developpement des Nouvelles Technologies).

\section{Consent for publication}

Not applicable.

\section{Competing interests}

Jan Baan and Peter Bramlage received research funding from Edwards Lifesciences, as did Andrea Ungar. Jean-Bernard Masson is a consultant for Edwards Lifesciences. Jana Kurucova is an employee of Edwards Lifesciences. The other authors declare no conflict of interest in relation to this manuscript.

\section{Publisher's Note}

Springer Nature remains neutral with regard to jurisdictional claims in published maps and institutional affiliations.

\begin{abstract}
Author details
${ }^{1}$ Geriatric Intensive Care Unit, Department of Geriatrics and Medicine, Careggi Hospital and University of Florence, Florence, Italy. ${ }^{2}$ Internal Medicine, Section of Geriatric Medicine, Academic Medical Center, Amsterdam, Netherlands. ${ }^{3}$ Cardiology, Academic Medical Center, Amsterdam, Netherlands. ${ }^{4}$ Centre Hospitalier de I'Université de Montréal, Montréal, Canada. ${ }^{5}$ Institute for Pharmacology und Preventive Medicine, Cloppenburg, Germany. ${ }^{6}$ Edwards Lifesciences, Nyon, Switzerland. ${ }^{7}$ CNR-Institute of Neuroscience, Aging Branch, Padua, Italy. ${ }^{8}$ Department of Geriatrics, Inselspital, Bern University Hospital, University of Bern, Bern, Switzerland.
\end{abstract}

Received: 1 September 2017 Accepted: 14 December 2017 Published online: 04 January 2018

\section{References}

1. Bonow RO, Leon MB, Doshi D, Moat N. Management strategies and future challenges for aortic valve disease. Lancet (London, England). 2016; 387(10025):1312-23.

2. Leon MB, Smith CR, Mack M, Miller DC, Moses JW, Svensson LG, Tuzcu EM, Webb JG, Fontana GP, Makkar RR, et al. Transcatheter aortic-valve implantation for aortic stenosis in patients who cannot undergo surgery. N Engl J Med. 2010;363(17):1597-607

3. Schoenenberger AW, Stortecky S, Neumann S, Moser A, Juni P, Carrel T, Huber C, Gandon M, Bischoff S, Schoenenberger CM, et al. Predictors of functional decline in elderly patients undergoing transcatheter aortic valve implantation (TAVI). Eur Heart J. 2013;34(9):684-92.

4. Piazza N, Wenaweser $P$, van Gameren M, Pilgrim T, Tzikas A, Otten A, Nuis R Onuma Y, Cheng JM, Kappetein AP, et al. Relationship between the logistic EuroSCORE and the society of thoracic surgeons predicted risk of mortality score in patients implanted with the CoreValve ReValving system-a BernRotterdam study. Am Heart J. 2010;159(2):323-9.

5. Ben-Dor I, Gaglia MA Jr, Barbash IM, Maluenda G, Hauville C, Gonzalez MA Sardi G, Laynez-Carnicero A, Torguson R, Okubagzi P, et al. Comparison between Society of Thoracic Surgeons score and logistic EuroSCORE for predicting mortality in patients referred for transcatheter aortic valve implantation. Cardiovasc Revasc Med. 2011:12(6):345-9.

6. Afilalo J, Mottillo S, Eisenberg MJ, Alexander KP, Noiseux N, Perrault LP, Morin JF, Langlois Y, Ohayon SM, Monette J, et al. Addition of frailty and disability to cardiac surgery risk scores identifies elderly patients at high risk of mortality or major morbidity. Circ Cardiovasc Qual Outcomes. 2012;5(2): 222-8.

7. Afilalo J, Eisenberg MJ, Morin JF, Bergman H, Monette J, Noiseux N, Perrault $L P$, Alexander KP, Langlois $Y$, Dendukuri $N$, et al. Gait speed as an incremental predictor of mortality and major morbidity in elderly patients undergoing cardiac surgery. J Am Coll Cardiol. 2010;56(20):1668-76.

8. Otto CM, Kumbhani DJ, Alexander KP, Calhoon JH, Desai MY, Kaul S, Lee JC, Ruiz CE, Vassileva CM. 2017 ACC expert consensus decision pathway for transcatheter aortic valve replacement in the management of adults with aortic stenosis: a report of the American College of Cardiology Task Force on clinical expert consensus documents. J Am Coll Cardiol. 2017;69(10): 1313-46.

9. Ungar A, Bramlage P, Thoenes M, Zannoni S, Michel JP. A call to action geriatricians' experience in treatment of aortic stenosis and involvement in transcatheter aortic valve implantation. Eur Geriatr Med. 2013;4(3):176-82.

10. Ellis $\mathrm{G}$, Langhorne P. Comprehensive geriatric assessment for older hospital patients. Br Med Bull. 2004;71:45-59.

11. Lilamand M, Dumonteil N, Nourhashemi F, Hanon O, Marcheix B, Toulza O, Elmalem S, van Kan GA, Raynaud-Simon A, Vellas B, et al. Gait speed and comprehensive geriatric assessment: two keys to improve the management of older persons with aortic stenosis. Int J Cardiol. 2014;173(3):580-2.

12. Pilotto A, Ferrucci L, Franceschi M, D'Ambrosio LP, Scarcelli C, Cascavilla L, Paris F, Placentino G, Seripa D, Dallapiccola B, et al. Development and validation of a multidimensional prognostic index for one-year mortality from comprehensive geriatric assessment in hospitalized older patients. Rejuvenation Res. 2008;11(1):151-61.

13. Pilotto A, Rengo F, Marchionni N, Sancarlo D, Fontana A, Panza F, Ferrucci L. Comparing the prognostic accuracy for all-cause mortality of frailty instruments: a multicentre 1-year follow-up in hospitalized older patients. PLoS One. 2012;7(1):e29090.

14. Stortecky S, Schoenenberger AW, Moser A, Kalesan B, Juni P, Carrel T, Bischoff S, Schoenenberger CM, Stuck AE, Windecker S, et al. Evaluation of multidimensional geriatric assessment as a predictor of mortality and cardiovascular events after transcatheter aortic valve implantation. JACC Cardiovasc Interv. 2012;5(5):489-96.

15. Green P, Woglom AE, Genereux P, Daneault B, Paradis JM, Schnell S, Hawkey M, Maurer MS, Kirtane AJ, Kodali S, et al. The impact of frailty status on survival after transcatheter aortic valve replacement in older adults with severe aortic stenosis: a single-center experience. JACC Cardiovasc Interv. 2012;5(9):974-81.

16. Kamga $M$, Boland B, Cornette $P$, Beeckmans $M$, De Meester C, Chenu $P$, Gurne O, Renkin J, Kefer J. Impact of frailty scores on outcome of octogenarian patients undergoing transcatheter aortic valve implantation. Acta Cardiol. 2013;68(6):599-606.

17. Schoenenberger AW, Werner N, Bramlage P, Martinez-Selles M, Maggi S, Bauernschmitt R, Thoenes M, Kurucova J, Michel JP, Ungar A. Comprehensive geriatric assessment in patients undergoing transcatheter aortic valve implantation-rationale and design of the European CGA-TAVI registry. Eur Geriatr Med. 2014;5(1):8-13.

18. Katz S, Downs TD, Cash HR, Grotz RC. Progress in development of the index of ADL. The Gerontologist. 1970;10(1):20-30.

19. Katz S, Ford AB, Moskowitz RW, Jackson BA, Jaffe MW. Studies of illness in the aged. The index of ADL: a standardized measure of biological and psychosocial function. JAMA. 1963;185:914-9.

20. Lawton MP, Brody EM. Assessment of older people: self-maintaining and instrumental activities of daily living. The Gerontologist. 1969;9(3):179-86.

21. Pfeiffer E. A short portable mental status questionnaire for the assessment of organic brain deficit in elderly patients. J Am Geriatr Soc. 1975;23(10): 433-41.

22. Conwell Y, Forbes NT, Cox C, Caine ED. Validation of a measure of physical illness burden at autopsy: the cumulative illness rating scale. J Am Geriatr Soc. 1993:41(1):38-41.

23. Linn BS, Linn MW, Gurel L. Cumulative illness rating scale. J Am Geriatr Soc. 1968;16(5):622-6.

24. Vellas B, Guigoz Y, Garry PJ, Nourhashemi F, Bennahum D, Lauque S, Albarede $J$. The Mini Nutritional Assessment (MNA) and its use in grading the nutritional state of elderly patients. Nutrition (Burbank, Los Angeles County, Calif). 1999;15(2):116-22.

25. Bliss MR, McLaren R, Exton-Smith AN. Mattresses for preventing pressure sores in geriatric patients. Mon Bull Minist Health Public Health Lab Serv. 1966:25:238-68.

26. Di Bari M, Balzi D, Roberts AT, Barchielli A, Fumagalli S, Ungar A, Bandinelli S De Alfieri W, Gabbani L, Marchionni N. Prognostic stratification of older persons based on simple administrative data: development and validation of the "Silver Code", to be used in emergency department triage. J Gerontol A Biol Sci Med Sci. 2010;65(2):159-64.

27. Guralnik JM, Simonsick EM, Ferrucci L, Glynn RJ, Berkman LF, Blazer DG, Scherr PA, Wallace RB. A short physical performance battery assessing lower extremity function: association with self-reported disability and prediction of mortality and nursing home admission. J Gerontol. 1994;49(2):M85-94. 
28. Kappetein AP, Head SJ, Genereux P, Piazza N, van Mieghem NM, Blackstone EH, Brott TG, Cohen DJ, Cutlip DE, van Es GA, et al. Updated standardized endpoint definitions for transcatheter aortic valve implantation: the valve academic research Consortium-2 consensus document (VARC-2). Eur Cardiothorac Surg. 2012;42(5):S45-60.

29. Kodali S, Thourani VH, White J, Malaisrie SC, Lim S, Greason KL, Williams M, Guerrero M, Eisenhauer AC, Kapadia S, et al. Early clinical and echocardiographic outcomes after SAPIEN 3 transcatheter aortic valve replacement in inoperable, high-risk and intermediate-risk patients with aortic stenosis. Eur Heart J. 2016;37(28):2252-62.

30. Wendler O, Schymik G, Treede H, Baumgartner H, Dumonteil N, Ihlberg L, Neumann FJ, Tarantini G, Zamarano JL, Vahanian A. SOURCE 3 registry: design and 30-day results of the European Postapproval registry of the latest generation of the SAPIEN 3 transcatheter heart valve. Circulation. 2017; 135(12):1123-32.

31. Chieffo A, Petronio AS, Mehilli J, Chandrasekhar J, Sartori S, Lefèvre T, Presbitero P, Capranzano P, Tchetche D, ladanza A, et al. Acute and 30-day outcomes in women after TAVR: results from the WIN-TAVI (Women's INternational Transcatheter Aortic Valve Implantation) real-world registry. J Am Coll Cardiol Intv. 2016;9(15):1589-600.

32. Wenaweser P, Stortecky S, Heg D, Tueller D, Nietlispach F, Falk V, Pedrazzini GB, Jeger RV, Reuthebuch O, Carrel T, et al. Short-term clinical outcomes among patients undergoing transcatheter aortic valve implantation in Switzerland: the Swiss TAVI registry. Eurolntervention. 2014;10(8):982-9.

33. Chieffo A, Van Mieghem NM, Tchetche D, Dumonteil N, Giustino G, Van der Boon RMA, Pierri A, Marcheix B, Misuraca L, Serruys PW, et al. Impact of mixed aortic valve stenosis on VARC-2 outcomes and postprocedural aortic regurgitation in patients undergoing transcatheter aortic valve implantation. Catheter Cardiovasc Interv. 2015;86(5):875-85.

34. Leon MB, Smith CR, Mack MJ, Makkar RR, Svensson LG, Kodali SK, Thouran VH, Tuzcu EM, Miller DC, Herrmann HC, et al. Transcatheter or surgical aortic-valve replacement in intermediate-risk patients. N Engl J Med. 2016; 374(17):1609-20.

35. Cockburn J, Dooley M, Trivedi U, De Belder A, Hildick-Smith D. A comparison between surgical risk scores for predicting outcome in patients undergoing transcatheter aortic valve implantation. J Cardiovasc Surg (Torino). 2017;58(3):467-72. doi:https://doi.org/10.23736/S0021-9509.16. 09339-3. Epub 2016 Mar 16.

36. Collas V, Chong YM, Rodrigus I, Vandewoude M, Bosmans J. Predictive mortality estimation in older patients undergoing TAVI comparison of the logistic EuroSCORE, EuroSCORE II and STS-score. Eur Geriatr Med. 2015;6(1):11-4.

37. Giantin V, Valentini E, lasevoli M, Falci C, Siviero P, De Luca E, Maggi S, Martella B, Orrù G, Crepaldi G, et al. Does the Multidimensional Prognostic Index (MPI), based on a Comprehensive Geriatric Assessment (CGA), predict mortality in cancer patients? Results of a prospective observational trial. J Geriatr Oncol. 2013;4(3):208-17.

38. Pilotto A, Addante F, Ferrucci L, Leandro G, D'Onofrio G, Corritore M, Niro V Scarcelli C, Dallapiccola B, Franceschi M. The multidimensional prognostic index predicts short- and long-term mortality in hospitalized geriatric patients with pneumonia. J Gerontol A Biol Sci Med Sci. 2009;64(8):880-7.

39. Pilotto A, Addante F, Franceschi M, Leandro G, Rengo G, D'Ambrosio P, Longo MG, Rengo F, Pellegrini F, Dallapiccola B, et al. Multidimensional prognostic index based on a comprehensive geriatric assessment predicts short-term mortality in older patients with heart failure. Circ Heart Fail. 2010; 3(1):14-20.

40. Sancarlo D, Pilotto A, Panza F, Copetti M, Longo MG, D'Ambrosio P, D'Onofrio G, Ferrucci L, Pilotto A. A Multidimensional Prognostic Index (MPI) based on a comprehensive geriatric assessment predicts short- and longterm all-cause mortality in older hospitalized patients with transient ischemic attack. J Neurol. 2012;259(4):670-8.

41. Sundermann S, Dademasch A, Rastan A, Praetorius J, Rodriguez H, Walther T, Mohr FW, Falk V. One-year follow-up of patients undergoing elective cardiac surgery assessed with the comprehensive assessment of frailty test and its simplified form. Interact Cardiovasc Thorac Surg. 2011;13(2):119-23.

42. Arnold SV, Reynolds MR, Lei Y, Magnuson EA, Kirtane AJ, Kodali SK, Zajarias A, Thourani VH, Green P, Rodes-Cabau J, et al. Predictors of poor outcomes after transcatheter aortic valve replacement: results from the PARTNER (Placement of Aortic Transcatheter Valve) trial. Circulation. 2014;129(25):2682-90.

43. Arnold SV, Afilalo J, Spertus JA, Tang Y, Baron SJ, Jones PG, Reardon MJ, Yakubov SJ, Adams DH, Cohen DJ. Prediction of poor outcome after transcatheter aortic valve replacement. J Am Coll Cardiol. 2016;68(17):1868-77.
44. Afilalo J, Kim S, O'Brien S, Brennan JM, Edwards FH, Mack MJ, McClurken JB, Cleveland JC Jr, Smith PK, Shahian DM, et al. Gait speed and operative mortality in older adults following cardiac surgery. JAMA Cardiol. 2016;1(3): 314-21.

45. Alfredsson J, Stebbins A, Brennan JM, Matsouaka R, Afilalo J, Peterson ED, Vemulapalli S, Rumsfeld JS, Shahian D, Mack MJ, et al. Gait speed predicts 30-day mortality after transcatheter aortic valve replacement: results from the Society of Thoracic Surgeons/American College of Cardiology Transcatheter Valve Therapy Registry. Circulation. 2016;133(14):1351-9.

46. Di Bari M, Salvi F, Roberts AT, Balzi D, Lorenzetti B, Morichi V, Rossi L, Lattanzio F, Marchionni N. Prognostic stratification of elderly patients in the emergency department: a comparison between the "Identification of Seniors at Risk" and the "Silver Code". J Gerontol A Biol Sci Med Sci. 2012; 67(5):544-50.

\section{Submit your next manuscript to BioMed Central and we will help you at every step:}

- We accept pre-submission inquiries

- Our selector tool helps you to find the most relevant journal

- We provide round the clock customer support

- Convenient online submission

- Thorough peer review

- Inclusion in PubMed and all major indexing services

- Maximum visibility for your research

Submit your manuscript at www.biomedcentral.com/submit
C Biomed Central 